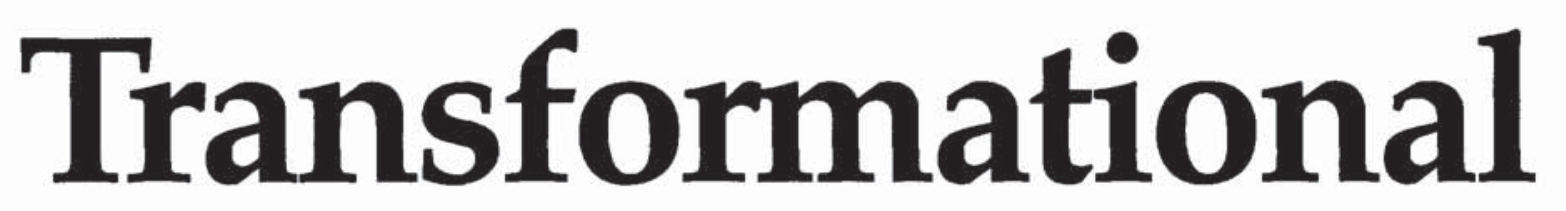

Leaders

\title{
in the Hospitality Industry
}

\section{The classic metaphor of the manager as one who fights fires may need to be replaced by that of one who focuses on fire prevention.}

by J. Bruce Tracey and Timothy R. Hinkin

THE LODGING INDUSTRY has a strong culture, and many of its traditions have changed little over the last several decades. Most of its managers, for instance, were trained in the classical management style, which emphasized the functions of planning, organizing, leading, and controlling. In that paradigm, formal rules and regulations guide decision making and

๑ 1994, Cornell University ensure organizational stability. Work is done "by the book." Labor is divided by functional area, and work is broken into discrete tasks, which enables managers to replace employees by training new ones as needed. One's rank in the hierarchical structure determines authority, and decision making tends to be centralized, coming primarily from the top of the organization.

The classical management system results in strict adherence to rules and regulations; there is little room for individual freedom, creativity, and innovation. Decision making can be painfully slow, especially for any situation that is not covered by rules and regulations and has to make its way up and down the hierarchy before action can be taken. There is a tendency for empire building, as control of resources and personnel reflects importance in the organi-

J. Bruce Tracey, Ph.D., assistant professor of management, and Timothy R. Hinkin, Ph.D., associate professor of management, both at Cornell's School of Hotel Administration, express their thanks to Cornell Professor Peter Rainsford, Ph.D., for his help in collecting the data for this report. 
zation. The system demands compliance and often rewards perseverance rather than performance. Those who reach the top of the hierarchy tend to view the world in the same way as their predecessors. That perpetuates a system where things are done the way they have always been done.

Such a system is effective in an environment where competition is relatively benign, labor is inexpensive and plentiful, and consumer demands are stable and predictable. If such an environment ever existed, it certainly does not exist today. More than ever, organizations in the lodging industry are faced with major challenges both from the external environment and from within the organization.

Adequate and appropriate labor, for instance, has become a challenge. Robert Porreca, a senior financial analyst for Dun and Bradstreet's Analytical Services, recently reported strong evidence of a labor shortage. ${ }^{1}$ Porreca's forecast showed that while the number of jobs in the lodging industry is expected to grow to about 20 percent of the nation's workforce by the year 2000 , there will be less than 15 percent of the traditional labor supply (i.e., workers aged 15 to 24 years old) to fill the demand. The gap will force many hospitality organizations to be creative in recruiting and selecting nontraditional employees and to develop innovative strategies for increasing retention and reducing turnover.

Competition has also become keen. Porreca noted some serious financial concerns for hospitality firms, especially regarding occupancy and room rates: "The oversupply of rooms over the

${ }^{1}$ R.A. Porreca, Lodging: An Industry Overview (New York: Dun and Bradstreet, 1990).

\section{EXHIBIT 1 Transactional and transformational leadership}

\begin{tabular}{l|l|l} 
& \multicolumn{1}{|c|}{ TransaCTIONAL } & \multicolumn{1}{|c}{ TRANSFormational } \\
\hline Time orientation & Short, today & Long, future \\
Coordination mechanism & Rules and regulations & Goal and value congruence \\
Communication & Vertical, downward & Multidirectional \\
Focus & Financial goals & Customer (internal and external) \\
Reward systems & Organizational, extrinsic & Personal, intrinsic \\
Source of power & From position & From below \\
Decision making & Centralized, downward & Dispersed, upward \\
Employees & Replaceable commodity & Developable resource \\
Compliance mechanism & Directive & Rational explanation \\
Attitude toward change & Avoidable, resistant, status quo & Inevitable, embrace \\
Guiding mechanism & Profit & Vision and values \\
Control & Rigid conformity & Self-control \\
Perspective & Internal & External \\
Task design & Compartmentalized, individual & Enriched, groups \\
&
\end{tabular}

Source: Adapted from work by N.M. Tichy and M.A. Devanna, The Transformational Leader (New York: John Wiley \& Sons, Inc., 1986); and B.B. Bass and B.J. Avolio, Improving Organizational Effectiveness through Transformational Leadership (Thousand Oaks, CA: Sage, 1994).

past few years has caused a squeeze on the profits of many firms in the industry." 2 That concern was echoed by Dave Arnold, a regional director for PKF Consulting. In a recent article Arnold showed a substantial decline in lodging revenues and profits between 1989 and $1991{ }^{3}$ While the industry's fortunes improved considerably in 1992 , due primarily to cost reductions, the long-term future is suspect.

The shrinking labor force, tightening economic conditions, and other environmental influences have created demands on managers that did not exist a decade ago. Given that the role of cost cutting in turning things around is about over, and considering the labor-intensive nature of the hospitality industry, most improvements in performance and service quality will have to be made through strong leadership that will in turn result in the better use of human resources.

\footnotetext{
${ }^{2}$ Porreca, p. 36.

${ }^{3}$ D. Arnold, "Profits and Prices: A Lodging Analysis," The Cornell Hotel and Restaurant Administration Quarterly, Vol. 35, No. 1 (February 1994), pp. 30-33.
}

Transformational leadership is a way to advance the efficient use of human resources. As transformational leaders, hospitality managers must develop a strong sense of vision to clarify and communicate organizational objectives and create a working environment that fosters motivation, commitment, and continuous improvement. Those conditions may require extraordinary leaders who can transform their organizations to meet current and future challenges. ${ }^{4}$

With the current need for transformational leadership, the questions are whether any hospitality organizations' executives are using the visionary leadership practices necessary to cope with the current challenges and whether those leadership practices have a positive effect on important individual and organizational outcomes. This article reports the results of a study of leadership in a large hotelmanagement organization that has thrived under the adverse,

${ }^{4}$ N.M. Tichy and M.A. Devanna, The Transformational Leader (New York: John Wiley \& Sons, Inc., 1986). 
turbulent, and uncertain conditions experienced by the hospitality industry in the 1980 s and ' 90 s. Although we cannot categorically state that the leadership style of that organization has led to its financial success, the fact that it has performed well in recent years reflects positively on the top management group.

\section{Transformational Leadership}

Recent attempts have been made to develop an understanding of transformational leadership, which is distinct from the more classical, or transactional, leadership style. Transactional leadership is based on bureaucratic authority and legitimacy within the organization. A transactional leader tends to focus on task completion and employee compliance, relying heavily on organizational rewards and punishments to influence employee performance. In addition, transactional leaders tend to emphasize the daily operational needs of the organization.

By one definition, transformational leadership refers to "the process of influencing major changes in the attitudes and assumptions of organization members and building commitment for the organization's mission or objectives." This definition emphasizes the importance of the leader's characteristics, such as the leader's ability to define and articulate a vision for the organization and stresses the importance of the follower's acceptance of the credibility of the leader. Transformational leaders are concerned with a broad, holistic perspective of the current and future success of the organization.

${ }^{5}$ G.A. Yukl, Leadership in Organizations (Englewood Cliffs, NJ: Prentice-Hall, 1989), p. 204.
Transformational leadership is based on several components: the followers' perceptions of similarity with, and attraction to, the leader; the degree to which the leader addresses the concerns of the followers; and the extent to which the leader provides the followers with interesting and challenging tasks. Transformational leaders en-gender feelings of trust, loyalty, and respect from followers by (1) generating awareness and acceptance of the purpose and mission of the organization, (2) inducing them to transcend their own selfinterest for the sake of the organization, and (3) activating their higher-order needs. ${ }^{6} \mathrm{~A}$ clear vision inspires followers by enhancing the meaningfulness of their work and making them feel important to their organization. It helps people determine what is right and wrong, relevant and irrelevant in the organization. It enhances the efficiency and effectiveness of decision making while increasing employee discretion and responsibility. ${ }^{\text {? }}$

Transformational leadership frequently occurs during organizational crisis or major organizational change. At that juncture the leader convinces followers that the old ways of doing things are no longer effective, and a new direction for the organization is developed by redefining the mission. ${ }^{8}$ To maintain credibility and the trust and respect of followers, the leader must reinforce the vision by his or her behavior. In other words, to be effective, the

${ }^{6} \mathrm{~J}$. Seltzer and B. Bass, "Transformational Leadership: Beyond Initiation and Structure," Journal of Management, Vol. 16 (1990), pp. 693-704.

${ }^{7}$ W.G. Bennis and B. Nanus, Leaders: The Strategies for Taking Charge (New York City: Harper and Row, 1985).

${ }^{8}$ N.C. Roberts, "Transforming Leadership: Sources, Processes, Consequences" (paper presented at the annual meetings of the Academy of Management, Boston, 1984); and Tichy and Devanna. leader's words and actions must correspond. ${ }^{9}$ There is evidence that subordinates of transformational leaders experience higher performance, greater satisfaction, and less role conflict than subordinates of managers with a traditional management style. ${ }^{10}$

In sum, transformational leadership requires that a leader's vision, values, and behavior be consistent and focused on the future. The leader's values must be congruent with those of the followers, and the leader must be able to convince the followers that she or he knows where the organization is going and to engender the commitment of the followers in getting them there. Exhibit 1 presents a comparison of the classical transactional manager with a transformational leader.

\section{A Transformation in the Hospitality Industry}

An intensive review of the hospitality literature did not reveal a single article that specifically addressed charismatic or transformational leadership. However, in an article by Greger and Withiam, several leaders of top hospitality corporations, including Darryl Hartley-Leonard (Hyatt), Robert James (MHM), Horst Schulze (Ritz-Carlton), and Robert Conrad (Burger King), emphasized the importance of strong leadership that included transformational elements. ${ }^{11}$

\footnotetext{
${ }^{9}$ W.G. Bennis, "The Four Competencies of Leadership," Training and Development Journal, Vol. 38 (1984), pp. 14-19; and E.H. Schein, Organizational Culture and Leadership (San Francisco: Jossey-Bass, 1984).

${ }^{10}$ J.M. Howell and P. Frost, "A Laboratory Study of Charismatic Leadership," Organizational Behavior and Human Decision Processes, Vol. 43 (1989), pp. 243-269; R.T. Keller,

"Transformational Leadership and the Performance of Research and Development Project Groups," Journal of Management, Vol 18 (1992), pp. 489-502 ; and Seltzer and Bass. ${ }^{11}$ K.R. Greger and G. Withiam, "The View from the Helm: Hotel Execs Examine the Industry," The Cornell Hotel and Restaurant Administration Quarterly, Vol. 32, No. 4 (October 1991), pp. 18-35.
} 


\section{EXHIBIT 2 Mean ratings of leadership style}

\begin{tabular}{|c|c|c|}
\hline \multirow{2}{*}{$\begin{array}{c}\text { Strle Atraibutes } \\
\end{array}$} & \multicolumn{2}{|c|}{ Principal } \\
\hline & $\mathbf{A}$ & $\mathbf{E}$ \\
\hline $\begin{array}{l}\text { Effectiveness: technical competence, interpersonal skills, } \\
\text { procedural justice, organizational influence, communication, } \\
\text { and goal clarification }\end{array}$ & 2.77 & 4.59 \\
\hline $\begin{array}{l}\text { Attributed charisma: an ability to articulate a clear mission } \\
\text { and create trust among followers; may also be demonstrated } \\
\text { by a willingness to take high personal risks for the betterment } \\
\text { of the organization }\end{array}$ & 2.31 & 4.23 \\
\hline $\begin{array}{l}\text { Intellectual stimulation: the extent to which a leader provides } \\
\text { followers with challenging roles as they work to achieve } \\
\text { individual and organizational goals }\end{array}$ & 2.41 & 3.38 \\
\hline $\begin{array}{l}\text { Individualized consideration: personal attention to followers } \\
\text { and showing a concern for their needs }\end{array}$ & 1.51 & 3.41 \\
\hline Idealized influence: an emphasis on moral and ethical concerns & 2.07 & 3.91 \\
\hline $\begin{array}{l}\text { Inspirational leadership: personal examples of quality- } \\
\text { oriented behavior and instilling a sense of pride throughout } \\
\text { the organization }\end{array}$ & 2.87 & 3.63 \\
\hline $\begin{array}{l}\text { Contingent rewards: based on a leader's position of power } \\
\text { and the use of rewards for reinforcing outcomes of individual } \\
\text { performance }\end{array}$ & 1.52 & 2.94 \\
\hline $\begin{array}{l}\text { Active management by exception: a public, or overt, focus on } \\
\text { poor performance; involves paying attention to negative } \\
\text { outcomes of an individual's job performance }\end{array}$ & 3.05 & 2.20 \\
\hline $\begin{array}{l}\text { Passive management by exception: a lack of concern for } \\
\text { solving problems and not making decisions until a crisis } \\
\text { situation arises }\end{array}$ & 3.12 & 1.98 \\
\hline $\begin{array}{l}\text { Laissez-faire leadership: an avoidance of important issues } \\
\text { and a failure to act in a timely fashion during urgent situations }\end{array}$ & 3.02 & 1.55 \\
\hline
\end{tabular}

Many of the executives voiced a concern for creating a clear vision for their company and stated that developing an internal environment that enhances employee effectiveness was of primary importance.

In that article, several of the leaders stated that their primary functions were establishing longterm objectives and translating those objectives into clearly defined guidelines for employees. For example, Darryl HartleyLeonard viewed his role as being the "conscience of the company." He felt that an important aspect of his job was to enhance employee creativity and innovation and to set an example for his employees. Robert James noted the need to be an effective leader and that developing quality employees was central to success. Horst Schulze also emphasized the need for effective leadership, explaining that the leader's job is not only to develop a vision for the company but to make sure the employees understand the vision and stay focused on it.

It is understandable that a leader would focus on the importance of leadership for individual and organizational success. Evidence from case studies and empirical research conducted in the manufacturing sector, however, also supports the importance of visionary, transformational style of leadership..$^{12}$ Nevertheless, it is important to examine whether transformational leadership can be effective in the hospitality industry. Given the labor-intensive nature of the industry and the turbulent conditions it now faces, transformational leadership may be vital for long-term organizational success.

\footnotetext{
${ }^{12}$ G.A. Yukl.
}

\section{A Leadership Profile}

To examine the behavior associated with transformational leadership, we identified a hospitality organization that had been successful over the last several years. It is a hotel-management firm that was founded in the mid1980 s with contracts to manage six hotels. Today the company owns or manages 60 hotels located throughout the United States that employ over 5,000 people. Both sales and profits have grown in proportion to the increased number of management contracts. The company was started by five people who are still the principal partners and represent the leadership of the organization. All partners are active in the management of the organization.

We first asked the principal partners and 45 corporate staff members who work in the same offices as the partners to rate the effectiveness of each partner. There were six criteria: technical competence, interpersonal skills, procedural justice, organizational influence, communication, and goal clarification. Those criteria reflect multiple dimensions of a single, yet broadly defined, effectiveness construct. For each of the criteria, the respondents rated each leader on a scale of 1 (highly ineffective) to 7 (highly effective).

An analysis of variance revealed significant differences in overall effectiveness among the five leaders $(\mathrm{F}=10.97, \mathrm{df}=4$, $p<.01$ ). Three of the leaders were rated highly effective, one was rated moderately effective, and one was rated quite ineffective. The most effective leader was uniformly high on each of the six criteria, as well as on the overall measure of effectiveness. Mean scores across the six criteria for 
the most effective leader ranged from a low of 4.40 for communication, to a high of 6.07 on interpersonal skills. In contrast, the most ineffective leader was rated uniformly low on each criterion, with mean scores ranging from 1.75 on interpersonal skills to 3.88 on technical competence.

Leadership style. Next, using Bass's Multifactor Leadership Questionnaire, the corporate staff and the partners rated each partner on several dimensions of transformational and transactional leadership. Bass's measure, which comprises 78 items, has shown adequate psychometric and measurement qualities in other studies. ${ }^{13}$

Transformational leadership was measured in terms of attributed charisma, intellectual stimulation, individualized consideration, idealized influence, and inspirational leadership. Transactional leadership was measured in terms of the use of contingent rewards, active and passive management by exception, and laissez-faire leadership. The respondents indicated how frequently the individual demonstrated the leadership behavior described. The response choices ranged from 1 (not at all) to 5 (frequently, if not always).

The questionnaires rated Principal E as most effective and Principal A as the least effective. Analyses comparing Principal A to Principal E, based on the average ratings provided by subordinates and peers, showed significant differences across each leadership dimension (all t-tests were significant at $\mathrm{p}<.05$ ). The mean ratings are shown in Exhibit 2.

The effective leader, Principal E, demonstrated significantly more transformational leadership behavior and less transactional

${ }^{13}$ Seltzer and Bass.

\section{EXHIBIT 3 Effective (transformational) leadership behavior}

Behaves in ways that are consistent with his or her expressed values

Shows determination to accomplish what she or he sets out to do

His or her actions build my respect for him or her

Displays extraordinary talent and competence in whatever she

or he undertakes

Displays conviction in his or her ideals, beliefs, and values

Goes beyond her or his self-interest for the good of our group

Sets high standards

Encourages addressing problems by using reasoning and evidence

rather than unsupported opinion

Instills pride in being associated with him or her

Considers the moral and ethical consequences of her or his decisions

Treats each of us as individuals with different needs, abilities, and aspirations

Listens attentively to my concerns

behavior than the ineffective leader, Principal A. Principal E was very high on attributed charisma and idealized influence, but the greatest difference between the two leaders was on individualized consideration. The ineffective leader was rated as very high in active management by exception, focusing on poor performance of employees.

The one discrepancy in the pattern was in the use of contingent rewards, which are viewed as a transactional behavior. The transactional leader, however, made less use of contingent rewards than the transformational leader. We found, however, that the use of contingent rewards, though it may be a transactional behavior, was perceived by subordinates as positive and effective. Most people want to know how they are performing on the job, and contingent rewards serve as both a reinforcer and a feedback mechanism and demonstrate concern for subordinates.

A similar pattern of leadership style and effectiveness ratings was found for the other three principals. The principals who were rated moderately effective were viewed as moderately transformational and demonstrated some transactional leadership behavior.
Leadership behavior. Of particular concern to the study was the identification of the specific behavior associated with both transformational and transactional leadership. Based on mean scores, we calculated the 12 most frequently reported leadership actions demonstrated by the effective and ineffective leaders. Again, there were clear differences between the two leaders.

The behavior exhibited most frequently by the effective leader was transformational. That leader was viewed as competent, showed a high degree of persistence in performing the job, had the organization's best interest in mind, and behaved consistently with expressed values and beliefs. In contrast, the ineffective leader's most frequently reported actions were all transactional. The person was viewed as reactive, spending most of the time "putting out fires," and focusing on mistakes rather than accomplishments. The comparison is reported in Exhibits 3 and 4.

The results show the importance of values, competence, and concern for employees and the organization to perceptions of effective leadership. The effective, transformational leader behaved in ways that were consistent with 


\section{EXHIBIT 4 Ineffective (transactional) leadership behavior}

Requires a failure to meet an objective for him or her to take action

Spends her or his time looking to "put out fires"

Makes clear what I can expect to receive if my performance meets designated

standards (reverse-scored, actual score 1.0)

Fails to follow up requests for assistance

Tells me what l've done wrong rather than what l've done right

Works out agreements with me on what I will receive if I do what

needs to be done (reverse-scored, actual score 1.14)

Is absent when needed

Focuses attention on irregularities, mistakes, exceptions, and

deviations from standards

Things have to go wrong for him or her to take action

Diverts her or his attention away from addressing work-related problems

Fails to intervene until problems become serious

Directs his or her attention toward failure to meet standards leaders communicate the organizational mission, followers gain an understanding of their individual roles as they help achieve the organization's mission. Role clarity was measured using a sixitem measure, developed by House and Rizzo, that asked respondents to indicate the extent to which they understood several aspects of their job. ${ }^{15}$

Transformational leadership should also result in followers' perceptions of effective and open communication. Without it, followers will not gain the necessary understanding of the organization's mission and their role in achieving it. We assessed openness of communication using a five-item measure developed by O'Reilly and Roberts that asked respondents to indicate the extent to which they agreed with statements regarding the free flow of communication within their organization..$^{16}$

Finally, if transformational leaders provide a clear direction for followers as they help the organization achieve its objectives, then followers' perceptions of satisfaction with a leader should be enhanced. We used a three-item version of the supervisor-satisfaction scale from the Minnesota Satisfaction Questionnaire, developed by Weiss, Dawis, and Lofquist, that asked respondents to rate the extent to which they were satisfied with each principal. ${ }^{17}$ It should be noted that prior studies have found

${ }^{15}$ R.J. House and J.R. Rizzo, "Role Conflict and Ambiguity as Critical Variables in a Model of Organizational Behavior," Organizational

Behavior and Human Performance, Vol. 16 (1972), pp. 467-505

${ }^{16}$ C.A. O'Reilly and K.H. Roberts, "Relationships among Components of Credibility and Communication Behaviors in Work Units," Journal of Applied Psychology, Vol. 1 (1976), pp. 99-102.

${ }^{17}$ D.J. Weiss, R.V. Dawis, G.W. England, and L.H. Lofquist, Manual for the Minnesota Satisfaction Questionnaire (Minneapolis: University of Minnesota, Industrial Relations Center, 1967). 
adequate reliability and validity estimates for these measures. Supporting evidence is reported in Price and Mueller's Handbook of Organizational Measurement. ${ }^{18}$

The analysis presents a clear picture of the relationship between both types of leadership and important follower perceptions. The transformationalleadership measure had a strong, positive correlation with all four outcome measures: $0.37(p<.01)$ with mission clarity; 0.25 $(\mathrm{p}<.05)$ with role clarity; 0.29 $(\mathrm{p}<.05)$ with openness of communication; and $0.40(\mathrm{p}<.01)$ with satisfaction with the leader.

In contrast, the measure of transactional leadership was not significantly related with any of the outcome measures. Moreover, although the two overall measures of leadership were not significantly related, the negative correlation ( -0.12 ; not significant) suggests that those who behave transformationally tend not to apply transactional behavior.

\section{The Importance of} Transformational Leadership

The hospitality industry has steadily changed over the past few decades, and that change has been dramatic in the past few years. Carving out niches, entering untapped markets, and maintaining any control at all of the external environment are becoming more and more difficult with every passing day. It seems unlikely that leaders and managers in the industry will be able to have an impact on external forces. Realistically, then, the primary methods for coping with the continuous flux and change must center on adaptation.

Adaptation does not mean, however, that one waits for

\footnotetext{
${ }^{18}$ J.L. Price and C.W. Mueller, The Handbook of Organizational Measurement (Marshfield, MA: Pitman, 1986).
}

things to happen. On the contrary, a proactive approach to guiding organizations must be taken. Leaders must maintain ongoing environmental scanning and planning for continuous change to develop new structures and mechanisms needed to cope with ever-changing competitive conditions. Part of that change is new methods of leading and managing that are focused on adaptation.

Management for adaptation, rather than control, requires a new form of leadership: transformational leadership. In this study we observed several positive outcomes of transformational leadership for the hospitality organization in question. The members of the organization are aware of Principal E's transformational leadership (even if they do not recognize it in those terms) and value that leadership as being strongly related to an understanding of where the organization is going and their role in that journey. That understanding and appreciation is in marked contrast to their assessment of transactional leadership.

This study's findings are limited to the hospitality organization in question. Moreover, it may be that under predictable and stable conditions transactional leadership practices would be effective for certain operational and strategic activities. We believe, however, that the external environment will remain turbulent and that transformational leadership will be important for enhancing individual and organizational effectiveness.

If the findings can be generalized to other companies, we can state that top executives who exhibit transformational leadership behavior are viewed as the most effective. The transformational leaders in this study demonstrated a clear sense of direction. They emphasized organizational objectives without losing sight of their followers' needs. They displayed strong values and ethics, characterized by attention to the consequences of their decisions. And they set high standards of performance by being effective themselves. In situations of uncertainty, if organizational members are to support the efforts of their leaders, they must know where they are going and understand what to do and why.

Being a manager and leader is no easy task, especially in today's competitive conditions. What has worked in the past is almost certainly not appropriate for the current and future challenges of the hospitality industry. The classic metaphor of the manager as one who fights fires may need to be replaced by that of one who focuses on fire prevention. Much of the conventional common sense of the past, characterized by phrases such as "If you don't hear from me, you know you're doing fine," "If it ain't broke, don't fix it," "No news is good news," and "Leave well enough alone" may need to be replaced by "The only thing that is constant is change."

It is the view of many hospitality managers that if they wait long enough, things will calm down and business as usual can be resumed. It is more likely, however, that the current complex and dynamic environment is here to stay, and management's ability to adapt to the turbulence will determine whether an organization survives. In such an environment the transformational leader is one who possesses the wisdom to recognize that change is inevitable and the courage to guide the organization by fostering an environment of growth and development. $\mathrm{CQ}$ 